\title{
Lessons Learned from a Rural Classroom Study: Transitioning from Concrete to Virtual Manipulatives to Teach Math Fact Fluency to Students with Learning Disabilities
}

\author{
Matthew Kabel ${ }^{1}$, Jiyung Hwang ${ }^{2}$ and Jiwon Hwang*3
}

* Corresponding author

E-mail: jhwang31@calstatela.edu

1. Department of Advanced Educational Studies, California State University, Bakersfield, CA, USA.

2. University of Missouri, MO, USA.

3. Division of Special Education and Counseling, California State University, Los Angeles, CA, USA.

\section{Article Info}

Received: March 9, 2021

Revised: May 3, 2021

Accepted: May 22, 2021

\subsection{3/jcsr.2021.7}

\section{How to cite}

Kabel, M., Hwang, J. \& Hwang, J. (2021). Lessons Learned from a Rural Classroom Study: Transitioning from Concrete to Virtual Manipulatives to Teach Math Fact Fluency to Students with Learning Disabilities. Journal of Curriculum Studies Research, 3(1), 42-68. https://doi.org/10.46303/jcsr.2021.7

\section{Copyright license}

This is an Open Access article distributed under the terms of the Creative Commons Attribution 4.0 International license (CC BY 4.0).

\begin{abstract}
As the use of technology has become more prevalent within the educational environment over the past decade, the emergence of the use of virtual manipulatives to support student learning in math has made transitioning to technology-infused math instruction unavoidable. Students in rural areas, however, have tended to receive far less technology-infused instruction due to the many challenges faced by rural schools that can adversely affect academic opportunities and disrupt equity in learning and teaching. In the current paper, we report on a classroom study conducted to examine whether the previously proven effects of concrete manipulatives can carry over into those of virtual manipulatives when teaching math fact fluency in multiplication and explored the potential for virtual manipulatives in rura classrooms from the teacher's perspective. Quantitative and qualitative results both indicated a promising potential for usage of virtual manipulatives, with meaningful implications for practitioners. The educational implications for designing and planning effective instruction incorporating virtual manipulatives are discussed.

\section{KEYWORDS}

Virtual manipulatives; rural school; math fact fluency; learning disabilities. 


\section{INTRODUCTION}

Mathematics has long been known to be a notoriously difficult subject particularly for students with learning disabilities (LD) because of many contributing factors including standards-based spiral nature of mathematics where topics increase in complexity and build upon previous learning, neuropsychological and academic characteristics of learning disability, and lack of instructional strategies or support (Fletcher \& Grigorenko, 2017; Becker et al., 2009; Jayanthi et al., 2008). According to the National Mathematics Advisory Panel (2008), mathematical proficiency requires an integrative set of understanding and skills in five major strands: conceptual understanding, procedural fluency, strategic competence, adaptive reasoning, and productive disposition. Previous studies have used different approaches to increase students' mathematics proficiency with an emphasis on at least one or two strands (e.g., Bottge et al., 2014; Rave \& Golightly, 2014).

Hwang and Riccomini (2016) identified three main instructional approaches - heuristic, semantic, and authentic - that categorize math interventions with relative focus among the five strands. Among these three instructional approaches, math interventions that use a heuristic approach (e.g., mnemonic, meta-cognitive, and cover-copy-comparison strategies) concentrate more on promoting procedural fluency by teaching students' skills to carry out the problemsolving process more flexibly and efficiently (Kelley, 2008; Ramos-Christian et al., 2008). While both mathematical understanding and procedural skill are equally important (Common Core State Standards Initiative, 2010), increasing math fact fluency, the basic skill of procedural fluency, has particularly gained a lot of attention when teaching students with LD. Because math fact fluency is a critical stepping-stone that affects the pursuit of math proficiency along with conceptual understanding (Rushton et al., 2016; Wu et al., 2013; Richland et al., 2012; Yesseldyke et al., 2005). Math fact fluency has often been defined by speed and accuracy in solving basic mathematical facts (i.e., the number of problems correctly solved per minute).

\section{Students with LD and Math Fact Fluency}

Previous studies have argued the importance of math fluency for students at all grade levels. Wu et al. (2013) found that children who develop math fact fluency at an early age are more likely to become proficient in mathematics later in life. Additionally, Rushton et al. (2016) stated that the mastery of math fluency has a positive impact on students' sense of efficacy, which can help lead to future math achievement. Several other studies (e.g., Berrett, \& Carter, 2018; Kelley, 2008; Ramos-Christian et al., 2008; Poncy \& Skinner, 2006) have also found that students who were not proficient in math fact fluency in elementary grades were less likely to succeed in later grades and that this lack of proficiency continued to be a significant barrier to pursuing advanced mathematics in middle and high school.

The mastery of math fact fluency, resulting from the achievement of automaticity of math facts, is even more critical and central to success throughout the mathematics curriculum for students with LD. Many students with LD lack working memory and executive functioning, 
have difficulties in organizing information and retrieving information from long-term memory, and present a series of non-strategic learner characteristics (e.g., unaware of possible steps to break the problem, unable to focus on a task, lack of persistence, and experience feeling of frustration, anxiety, and failure; Bryant et al., 2000; Morgan et al., 2019; Schmitz Jansen et al., 2019; Sideridis, 2005). Also, studies reported that attention deficits may be strongly related to LD condition, resulting in certain types of errors on a multi-digit computation task (i.e., operation switch errors) that were presented across subgroups of children with mathematical difficulties (Raghubar et al., 2009; Shaywitz et al., 1994). Moreover, according to Hirvonen et al. (2012)'s study where they used a bi-directional model to explain the relationship between academic and behavior, increased feeling of anxiety and frustration resulted from early academic failure led to less involvement in mathematical activities.

All of these make it difficult for students to do basic computations and break down problem-solving exercises (Miller \& Mercer, 1997; Geary et al., 2012), which further makes it challenging to meet the current rigorous math expectations that have shifted to a greater emphasis on solving complex real-life problems (National Council of Teachers in Mathematics [NCTM], 2019; Maccini et al., 2007). These challenges mean that achievement of automaticity of math facts is the most important skill that students with LD should have under their belts to compensate for neuro-psychological difficulties. In fact, students with math fact fluency are less anxious and more engaged in math activities, which increases their ability to master more difficult mathematical exercises (Billington \& Skinner, 2002; Cates \& Rhymer, 2003; RamosChristian et al., 2008).

\section{Using Multiple Representations to Teach Math}

The Center for Data-Driven Reform in Education (CDDRE; 2009) conducted a study where they reviewed evidence-based mathematical programs, interventions, and approaches and concluded that the incorporation of representations, cooperative learning, motivation, and/or classroom management in instruction had the most positive effects on student achievement in mathematics. Using representations, particularly manipulatives, was one of the most effective evidence-based strategies for students with disabilities followed by peer-assisted learning strategies (PALS). When teaching math facts, PALS can allow students to provide peer feedback as students deliver math facts to each other during timed sessions, which eventually leads to mastery of basic math facts; however, they are limited in their use in addressing current math standards as they focus more on memorization than on a conceptual understanding of math facts.

Many studies have demonstrated the positive effects of using multiple representations in various domains in mathematics (e.g., Hwang \& Riccomini, 2016; Codding et al., 2011; Flores \& Kaylor, 2007; Fuchs et al, 2011). Hwang, Riccomini, Hwang and Morano (2019) synthesized 22 experimental math intervention studies and found using multiple representations to be a significant instructional component to consider when designing math instruction. Types of 
representations take many forms, for example, concrete manipulatives, pictorials or drawings (i.e., semi-concrete manipulatives), schematic sketches of problem structures, and abstract symbols and notations. Two or more types of these representations are generally used in combination or they are used with other strategies (e.g., mnemonics).

Among the different types of representations, the NCTM (2019) recommended the integration of manipulatives at any grade level to aid in students' mathematical mastery but recommended them particularly for students with disabilities. Research has indicated that using manipulatives is beneficial in several aspects, one of which is improved retention of learned concepts and problem-solving skills (e.g., Ortiz, 2017). Additionally, studies have found that students who used manipulatives, no matter the grade level, ability level, or topic, outperformed students who did not use manipulatives (Clements, 1999; Ortiz, 2017; Witzel, Riccomini, \& Schneider, 2008). Because students with LD tend to struggle in math environments with traditional instruction, which is often rule-based teaching focusing on learning the algorithms of any given mathematical problem (Becker et al., 2009), manipulatives offer an evidence-based strategy that can aid in improving mathematical proficiency in several different math concepts (Agrawal \& Mori, 2016).

\section{Models for Multiple Representation Interventions}

Interventions that use manipulatives take various forms in terms of cognitive processing model (sequential vs. simultaneous), manipulative type (e.g., algebra block or tiles, actual objects, and stick), and delivery method (virtual vs. physical). Hwang, Riccomini, and Morano (2019) identified instructional sequences for types of cognitive processing in mathematical problemsolving interventions that served as bases to categorize representation interventions and examined how manipulatives were incorporated within interventions. These cognitive processing models were (a) concrete-representational-abstract (CRA), (b) integrated concreterepresentational-abstract (CRA-I), and (c) virtual-abstract (VA).

\section{Concrete Manipulatives}

The first two models, CRA and CRA-I, help students interact with a more abstract concept by effectively incorporating concrete manipulatives into instructions, but differ in terms of whether the three representation types ( $C, R$, and $A$ ) are provided sequentially or simultaneously. CRA's sequence involves students progressing through three stages of representation in order (i.e., $\mathrm{C}$ followed by the R and A stages; Hudson \& Miller, 2006; Yakubova et al., 2016). Students are first given an opportunity to manipulate concrete objects to solve specific mathematical problems, and as they reach mastery at the concrete level, students then progress to the representational stage where students then solve the same types of problems by drawing those manipulatives on paper. After mastery has been developed in the representational stage, students then move on to the abstract stage, the final stage, where students then solve the same types of problems using only mathematical notation and symbols. 
The CRA model is advantageous for the development of number fluency (Jones \& Tiller, 2017). CRA is an effective strategy for students that struggle with mathematical fluency, since the concrete and representational components support procedural knowledge as part of the abstract stage (Agrawal \& Morin, 2016; Miller \& Kaffar, 2011; Milton et al., 2019). Additionally, since the abstract stage in CRA focuses on the completion of a task, students are best supported when they are exposed to the mathematical notation along with a math problem in the concrete and representational stages (Flores, 2010). CRA has been well established as an effective strategy to support students with LD in solving various types of mathematical exercises and problems (Strickland \& Maccini, 2012; Satsangi \& Bouck, 2014; Shin et al., 2017).

Similar to CRA, CRA-I is a modification of CRA sequencing. Whereas CRA is delivered through stages and mastery of those stages, CRA-I involves the simultaneous presentation of a mathematical concept by integrating more than two stages at one time. Students use concrete manipulatives, drawing, and/or abstract notation at the same time. Use of CRA-I strategy helps students develop both procedural and conceptual knowledge leading to mathematical proficiency (Hudson \& Miller, 2006; Strickland \& Maccini, 2012; 2013; Strickland, 2016). Like CRA, the act of completing the concrete and representational phases, together with mathematical notation, supports math fact fluency.

\section{Virtual Manipulatives}

In addition to CRA and CRA-I, another cognitive processing type of mathematical problem solving is VA (Authors, 2019), where the $C$ and/or $R$ stages are replaced with the V stage. Over the last three decades, as the use of technology has become more prevalent within the educational environment (Bouck \& Flanagan, 2010; Nelson et al, 2016), an increasing number of mathematics practices have integrated technology (e.g., software program, apps, and ebooks) with an impact in creating instruction. In intervention designed using the VA model, students were provided a virtual space to manipulate and represent problems on a computer screen (e.g., MobyMax, ABCmouse, and BrainPOP).

Two types of virtual manipulatives are used in education: static manipulatives and dynamic manipulatives. Static manipulatives are representations of what concrete manipulatives look like as a picture so they are more like simple illustrations. Deubel (2000) explained that static manipulatives as not true virtual manipulatives and instead suggested that static manipulatives are more pictorial, like a picture or drawing. Another type of virtual manipulative is a dynamic representation of a concrete manipulative. Unlike static manipulatives, dynamic manipulatives are more dynamic, as their name indicates, in that they can be moved around, altered and adjusted, flipped around, and turned in different directions in ways that are similar to concrete manipulatives but in a virtual space where students manipulate them (Bouck \& Flanagan, 2010; Moyer et al., 2002; Spicer, 2000); therefore, they are considered similar to concrete manipulatives (Bouck \& Flanagan, 2010).

Although there has still been little research on virtual manipulatives when it comes to students with disabilities, recent studies have found that using virtual manipulatives can 
produce consistent or even better student outcomes than concrete manipulatives can, indicating that they are promising approach to transitioning to technology-infused math instruction (Bouck \& Flanagan, 2010). Studies have also indicated that virtual manipulatives were effective in helping students gain mathematical mastery of certain math concepts (e.g., area, perimeter, and algebra; Bouck \& Flanagan, 2010). The positive outcomes in these studies show that students may be able to access math concepts virtually through the use of the dynamic manipulatives, which students can use interactively (Bouck \& Flanagan, 2010; Reimer \& Moyer, 2005; Suh et al., 2005; Suh \& Moyer, 2007). Several major studies on virtual manipulatives have found that students who used virtual manipulatives made mathematical gains. In the study done by Bolyard and Moyer (2012), students using virtual manipulatives showed a significant increase in mathematical fluency of addition and subtraction. Additionally, students with LD have been found to benefit from the use of these new technologies, which have built-in dynamic action and constraints in order to teach mathematical concepts (Bouck et al., 2018; Satsangi \& Bouck, 2014).

\section{New Era in Teaching Mathematics}

Education has increasingly been saturated with technology, and the introduction of technology has been having an impact on educational settings in many aspects, especially dramatically as a result of the COVID-19 pandemic. For example, instruction have been held remotely using online conference tools such as Zoom and Google Hangout in synchronous or asynchronous mode. With the new technological methods and tools becoming part of classroom environments, it is important to consider whether educational goals in mathematics are being met when using these new platforms and methods of instruction and what their impact is on students both in achievement and perception in actual classroom environments (Cakir et al., 2009; Saylan et al., 2018).

Unlike concrete manipulatives, for which there is strong evidence for their use in helping students achieve mathematical mastery (e.g., developing fluency and mathematical understanding; Pratt \& Eddy, 2017), the use of virtual manipulatives is a relatively new and growing field in education. In fact, virtual manipulatives offer several benefits that may not be available with concrete manipulatives. One benefit is the availability of instructional materials for teachers at school sites for low or no cost, as opposed to the cost for teachers of providing concrete manipulatives. There are many different websites that offer virtual manipulatives for free (e.g., MobyMax; https://www.mobymax.com/). Additionally, adjusting the use of virtual manipulatives allows teachers to differentiate their instruction in more flexible ways, which is a benefit to special education teachers (Bouck \& Flanagan, 2010). Studies continue to be done on virtual manipulatives to demonstrate these effects as best practices for educating students with disabilities (Bouck \& Flanagan, 2010; Maccini \& Gagnon, 2000; Satsangi et al., 2018).

Given the current educational trend and social situation, using technology in education settings is now unavoidable; therefore, the challenges of using virtual manipulatives need to be 
addressed (e.g., need for training, unfamiliarity, and perceptions toward technology), and future directions for their effective use in classroom settings need to be sought. Additionally, too little research has been done for students with disabilities, particularly for those in rural areas, which may widen the achievement gap between them and students without disabilities in the era of digital and virtual learning. Students living in rural areas generally have limited access to technology and internet access at home (National Center for Education Statistics [NCES], 2018a; $2018 \mathrm{~b})$ and rarely receive technology-infused instruction at school due to the many challenges faced by rural schools in terms of technology accessibility, implementation, and resources. These challenges adversely affect academic opportunities for students, which may also disrupt equity in learning and teaching. The current study aims to address this gap by conducting a classroom study in rural classrooms with students with LD.

\section{Study Purpose}

Recognizing the increasing need and promising evidence for using technology to teach mathematics concepts and skills, the main goals of the current study are (a) to examine whether the previously proven effects of concrete manipulatives on students' math fact fluency can carry over into those of virtual manipulatives, (b) to examine virtual manipulatives' potential for use in classroom settings based on the perceptions of students and teachers, and (c) to explore future directions for practices for effective use of virtual manipulatives in teaching math for students with LD in rural schools. To achieve (a), we compared students' performance in math fact fluency on one-digit by one-digit multiplication problems between two types of manipulatives: virtual and concrete. Our purpose goes beyond the mere comparison of two manipulatives to how to improve math instruction in remote/virtual learning environments. To achieve (b), we examined students' perceptions and attitudes toward the use of technology (e.g., how much they think virtual manipulatives helped them in their studies) and special education teachers' perceptions of the efficacy and feasibility of using virtual manipulatives in rural classroom settings. The following specific research questions were addressed:

1. How does the number of multiplication problems that students with LD solve correctly per minute (i.e., fluency) differ between the use of virtual and concrete manipulatives in math instruction?

2. What are the perceptions of students with LD on the use of virtual manipulatives, and what are teachers' perceptions about the efficacy (i.e., impact on students' performance) and feasibility of the use of virtual manipulatives in rural classroom settings? 


\section{METHOD}

\section{Participants and Setting}

Participants were recruited from one middle school in a mountain community in a rural area of Southern California that serves Grades 6 to 8. As shown in Table 1, eight sixth-grade students (age range 11-13) who were identified as having LD specifically in mathematics participated in this study. All students had at least one individualized education program (IEP) goal in math, and of the eight students, two had comorbidity in addition to their primary LD diagnosis (speech and language impairment and other health impairment). All eight students were enrolled in a resource specialist program (RSP), a mainstream program where students spent part of their day in special education classes for disciplines including math $(n=8)$ and/or English language arts $(n=6)$ and spent the other part of the day in general education classes for disciplines including physical education, science, and social studies. Students had no prior experience using virtual manipulatives to learn any mathematics domain.

Table 1: Participant Demographics

\begin{tabular}{|c|c|}
\hline & $\mathrm{N}$ \\
\hline \multicolumn{2}{|l|}{ Grade (Age) } \\
\hline $6(11-12)$ & 8 \\
\hline \multicolumn{2}{|l|}{ Gender } \\
\hline Female & 3 \\
\hline \multicolumn{2}{|l|}{ Ethnicity } \\
\hline White & 5 \\
\hline Hispanic/Latino & 3 \\
\hline \multicolumn{2}{|l|}{ Disability } \\
\hline SLD ${ }^{\text {a }}$ Only & 6 \\
\hline SLD with Comorbid Conditions & $2\left(1=\mathrm{OHI}^{\mathrm{e}} ; 1=\mathrm{SL}^{f}\right)$ \\
\hline \multicolumn{2}{|l|}{ IEP Goal } \\
\hline Math Only & 2 \\
\hline Math and Reading & 6 \\
\hline \multicolumn{2}{|l|}{ Cognitive Skills } \\
\hline WISC-IV ${ }^{b}$ & $95(13.04)$ \\
\hline Working Memory & $90(13.54)$ \\
\hline Processing Speed & $86.25(13.20)$ \\
\hline TONI-4c & $102.67(9.14)$ \\
\hline \multicolumn{2}{|l|}{ Academic Achievement } \\
\hline \multicolumn{2}{|l|}{ WIAT-III } \\
\hline Math Problem Solving & $78.13(11.37)$ \\
\hline Numerical Operations & $83.75(11.26)$ \\
\hline Math Fluency Addition & $78.75(11.73)$ \\
\hline Math Fluency Subtraction & $74.5(6.82)$ \\
\hline Math Fluency Multiplication & $81.88(4.36)$ \\
\hline
\end{tabular}




\section{Action Research Model}

To address the research questions, an action research model was used. Action research is a type of research that uses an experimental approach in traditional research (e.g., data collection, analysis, and interpretation) to address practical situations and set up action plans (BradburyHuang, 2010; Lewin, 1946). Action research is beneficial in that it helps teachers become empowered by advancing their teaching by means of systematic implementation of evidencebased practices and data-based decision making. Additionally, because action research is directly involved in and relates to real and unstructured (i.e., less constraint and controlled by research design) classroom settings, it provides useful implications for teachers, who are the primary consumers of the findings. To respond to the current increasing need for using technology in education and to help with the urgent need for virtual instruction as a result of the COVID-19 pandemic that began in 2020, we chose an action research model to provide relevant findings for teachers in their immediate and familiar environments. Findings from an action research model can also have implications for future directions and guidance for administrators, curriculum developers, and researchers.

Several studies have proposed that action research be conducted in a spiral and recursive cycle (Hine, 2013; McMillan, 2008; Sagor, 2000). For example, Sagor (2000) proposed four stages: clarification of vision and targeted improvement, identification of action for desired results, implementation of actions and data collection, and reflection on results. Similar to previous models of action research, Taylor (2019) recently suggested four stages for an action research cycle: identify, plan, act, and decide. Taylor and colleagues (Taylor, 2019; Taylor \& Moohr, 2018) also recommended that basic action research language (e.g., independent variable, dependent variable, and markedly different) should be used to better articulate research problems, resolve situations and concerns, conduct systematic research, and develop professional partnerships with colleagues and relevant researchers. In the identify stage, problems, target population, and independent and dependent variables are identified. In the plan stage, theories and strategies that will be used to implement are identified, and research questions are developed that will guide an investigation. In act stage, data is collected (baseline and intervention, or pre and post) and analyzed using appropriate techniques (e.g., data visualization, bar graph, or line graph). In the decide stage, findings are examined to adjust interventions and suggest future directions of intervention. See Table 2 for how the current study aligns with the four stages of Taylor's (2019) action research cycle. 
Table 2: Four Stages of Action Research

\begin{tabular}{cl}
\hline $\begin{array}{c}\text { Action Research } \\
\text { Stages }\end{array}$ & \multicolumn{1}{c}{ Description of Current Study } \\
\hline Identify & $\begin{array}{l}\text { Problem is undiscovered benefits of use of virtual manipulatives to teach math } \\
\text { fact multiplication fluency to middle students with LD in rural classroom. } \\
\text { Independent variable is manipulative type (virtual vs. concrete manipulatives; } \\
\text { and dependent variables are (a) single-digit multiplication fact fluency (the } \\
\text { number of problems correctly solved per minute); and (b) single-digit by } \\
\text { double-digit multiplication fact accuracy (the percentage of problems correctly } \\
\text { solved) }\end{array}$ \\
\hline Plan & $\begin{array}{l}\text { Interventions that use CRA-I model framework are implemented and two } \\
\text { manipulative types (concrete and virtual) are alternated. Research questions } \\
\\
\text { are developed. }\end{array}$ \\
\hline Interventions are implemented with ATD and data is collected for baseline, \\
& intervention, and maintenance phases. Results are analyzed with visual analysis \\
& technique and PND \\
\hline Decide & $\begin{array}{l}\text { Potential for the use of virtual manipulatives is sought compared to concrete } \\
\text { manipulatives. Future direction for practices their effective use for students in } \\
\text { rural classroom is discussed. }\end{array}$ \\
\hline
\end{tabular}

\section{Dependent Variables and Measures}

The dependent variables used to measure students' performance were (a) multiplication fact fluency measured by the number of correctly solved single-digit multiplication problems per minute and (b) multiplication fact accuracy measured by the percentage of correctly solved twodigit (>20) by one-digit multiplication problems. The accuracy was additionally measured for the effects of virtual manipulatives but was not measured to compare effects of two different manipulatives types. The teacher developed 30 equivalent probes for math fact fluency and 10 probes for accuracy from the Math-Aid.com website (http://www.math-aids.com/) and administered formative assessments using these probes at the end of each session. For math fact fluency, students were given a $6 \mathrm{~cm}$ x $10 \mathrm{~cm}$ math worksheet consisting of 60 single-digit by single-digit multiplication problems with sums from 1 to 18. Problems were arranged in 6 rows across 10 columns with each problem being vertically presented. For math fact accuracy, students were given a worksheet consisting of 20 two-digit by single-digit multiplication problems arranged in 5 rows across 4 columns. Math fact accuracy was measured after every five consecutive sessions. The number of problems per probe (60 and 20) was chosen by the teacher to avoid ceiling effects based on the students' previous performance.

\section{Data Collection Procedures}

A single-case alternating treatments design (ATD) was used to compare the effectiveness of virtual and concrete manipulatives on the math fact fluency in single-digit multiplication. ATD allows for the comparison of two or more treatments, and these effects can be found intuitively and quickly; therefore, it is an efficient design that teachers can use as part of their instruction 
in classroom settings (Barlow \& Hayes, 1979; Coffee \& Kratochwill, 2015). Additionally, because our purpose was not only to examine whether virtual manipulatives could be promising alternatives to concrete manipulatives but also to examine ways to improve math instruction using virtual manipulatives, particularly during virtual and remote instructions, ATD also allows examination of the effects of concrete manipulatives, which could be used in remote learning via virtual conference tools such as Zoom and Google Hangout.

\section{Baseline}

Students were assessed for multiplication fact fluency using one-digit by one-digit multiplication problems and for accuracy using two-digit by one-digit multiplication problems over three sessions (three probes for each condition totaling six probes) for three consecutive days in a special education classroom. During the baseline assessment, students were allowed to use any strategies that they had already used to help them solve the questions, but new strategies were neither introduced nor were prompts, either verbal or visual, provided.

\section{Intervention}

The interventions used the CRA-I intervention model framework, an instructional sequence using three stages of multiple representations (concrete or virtual, representational, and abstract representations), incorporated with explicit instruction components such as modeling, guided practice (e.g., I do - we do - you do) and clear identification of skills to learn. Research has indicated that mathematical instruction that is structured, guided, and explicit is highly effective in improving students' mathematical operations performance and problem-solving abilities when teaching students with LD (e.g., Maccini et al., 2007; Satsangi, Hammer, \& Hogan, 2018).

One of the two types of manipulatives, concrete or virtual, was used for the first stage of the sequence, and the types were alternated to compare their effects on multiplication fact fluency and accuracy. At the beginning of each intervention session, the teacher taught and modeled how to use each manipulative to solve a problem. Data was collected in the special education classroom and computer lab after each session. At the end of each 51-minute session, the teacher administered formative assessments (i.e., probes). Students were given a oneminute drill to measure math fact fluency in one-digit by one-digit multiplication for 10 sessions and 10 minutes for accuracy in two-digit by one-digit multiplication for 2 sessions (sessions 5 and 10).

Concrete Manipulatives. For the intervention with concrete manipulatives, the teacher modeled how to use concrete manipulatives to solve multiplication facts using an ELMO projection system that displayed what the teacher was doing on the classroom whiteboard (see Figure 1). The teacher showed students how to create an array using base-ten blocks and count the blocks in each row and column to get a total amount. For example, the teacher took 12 blocks out of the manipulative box and showed the class over the ELMO, saying, "if you make 3 rows and 4 columns of blocks in a rectangle, the total amount of blocks is 12 . Therefore, $3 \times 4=$ 12." The teacher demonstrated the usefulness of multiplication with manipulatives by telling 
students the total number of blocks they counted (12) is the answer for the multiplication fact $(3 \times 4)$. Then, the teacher and the students together created a $6 \times 7$ array using base-10 blocks and a product mat. Students were provided opportunities to practice different problems at the same level using blocks (e.g., $2 \times 3=6$ ). For example, students rolled dice three times and created single-digit by single-digit arrays using the numbers from the dice. The teacher and the paraprofessional walked around the room during instruction to help.

Figure 1: Concrete vs. Virtual Manipulatives

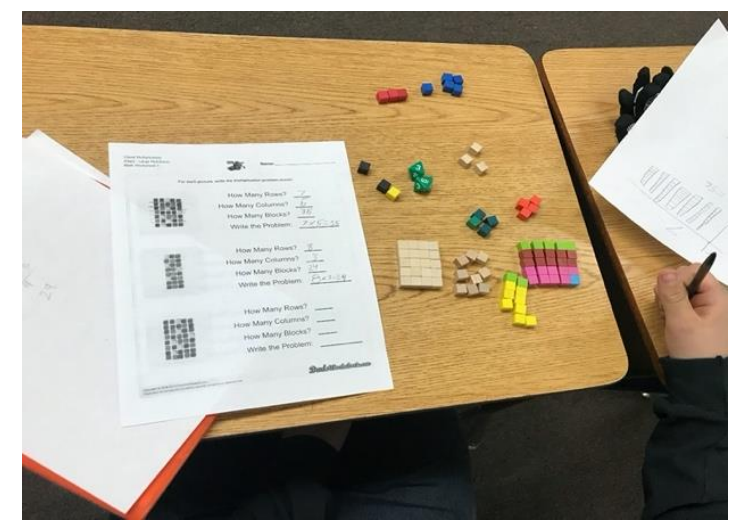

Concrete Manipulative

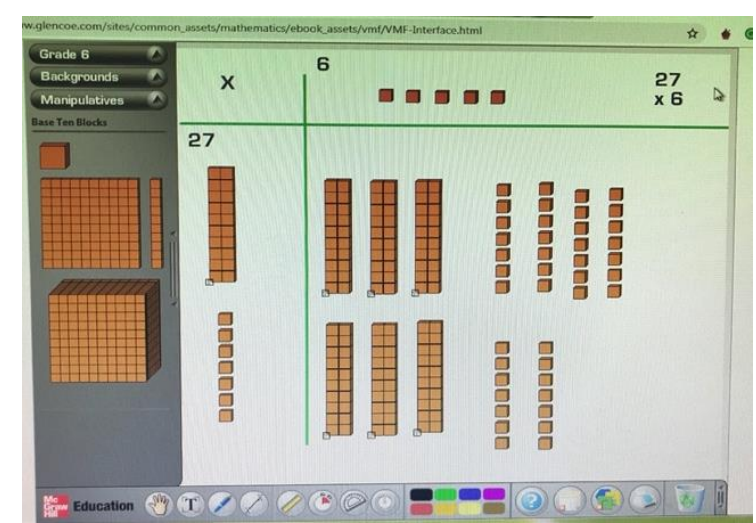

Virtual Manipulative

When the students achieved at a predetermined satisfactory level set by the teacher (correctness in 3 out of 5 trials), the teacher had the students draw the blocks on paper and create an array. The teacher showed the students how to solve multiplication problems using the same strategies, but instead of handheld manipulatives, they created drawings on paper. Students were provided a worksheet including questions asking how to read base-ten blocks and arrays from the drawings that were used as replacements for concrete manipulatives.

Virtual Manipulatives. Students used a desktop computer in a computer lab to access the McGraw Hill Virtual Manipulative website (see Figure 1). At the beginning of each session, the teacher let students explore and play on the webpage to get used to the use, movements, and structure of the virtual manipulatives. The structure of the interventions was constant, but concrete manipulatives were replaced with virtual manipulatives and hands-on activities were conducted on the computer screen. For example, the teacher modeled how to create an array using virtual blocks by dragging and dropping individual blocks and showed how to count the blocks in each row and column to get a total amount on the computer screen. Similar to the intervention with concrete manipulatives, when students achieved at a predetermined satisfactory level after a number of practices using virtual manipulatives go solve multiplication problems, the teacher had the students draw the blocks on paper and create an array. Mathematical notation and symbols were used at all stages of the intervention so that students could avoid disconnection among the representations. 
During both conditions of intervention, two supplementary worksheets were used to aid students' understanding and skills in using manipulatives to solve problems (both available at http://www.CommonCoreSheets.com/). One, called "partitioning rectangles," helped students understand the vocabulary used when working with manipulatives. The teacher used the partitioning rectangles worksheet to teach students the differences between rows and columns. Another one, called "rectangular arrays," was used to help students understand what an array is and how they can extract an answer for a problem using manipulatives. This worksheet showed students 14 different arrays and asked them make an equation from each different array. Both worksheets helped students concentrate on using manipulatives by reducing cognitive loads and accommodating other factors that may hinder or affect the usage of concrete manipulatives (e.g., math vocabulary and organization skills), which reduced any noise effects to detect pure effects of the use of concrete manipulatives.

\section{Maintenance}

The maintenance effect of the intervention on math fact fluency was measured two weeks after the intervention. All participants completed three probes on one-digit by one-digit multiplication facts over three sessions in a period of three days and one probe on two-digit by one-digit multiplication facts on the third day of the maintenance period. All probes were administered during the same math class by the same teacher.

\section{Data Analysis}

Intervention effects were analyzed using visual analysis and effect-size calculation. For visual analysis, we examined three aspects of the data: level, trend, and stability. First, median and mean levels were calculated within phases and their changes between phases were calculated. Second, trends within phases using the split-middle method of trend estimation were examined (Gast \& Ledford, 2014). In using the split-middle method, we divided data each phase into two halves, identified the intersections of the mid-rate and mid-date for each half, and drew a line passing through the intersections of the mid-date and mid-rate for each phase. Trend direction was determined to be either decelerating (deteriorating) or accelerating (improving) within each phase and summarized between phases for each intervention condition. Third, stability of data within phases was determined by calculating percentage of data points that fell within a $20 \%$ range of the median of each phase. Using an $80 \%$ stability criterion, we determined whether data was stable or variable in each phase.

For effect-size calculation, the percentage of non-overlapping data (PND) was calculated to supplement the visual analysis. PND is calculated by identifying the highest point in the baseline data, then calculating the total number of data points in the intervention phase that exceed the highest baseline data point (Scruggs, Mastropieri, \& Casto, 1987). We considered the intervention effect highly effective when the PND was greater than $90 \%$, mostly or fairly effective between $70 \%$ and $90 \%$, mildly effective between $50 \%$ and $70 \%$, and less effective or no observable effectiveness when less than $50 \%$ (Scruggs et al., 1987). 


\section{Social Validity}

To examine attitudes and perspectives toward the use of technology, particularly virtual manipulatives, students were given a survey using an online system at the end of the two-week intervention period. The survey consisted of five multiple-choice questions about prior experience using manipulatives, personal preferences and confidence level in using virtual and concrete manipulatives, and general attitude toward using technology in lessons. Two weeks after the conclusion of the intervention, the researcher interviewed two students so that they could elaborate on their responses to the survey and interviewed the teacher regarding the applicability and effectiveness of and potential for using virtual manipulatives in classroom settings.

\section{RESULTS}

While the use of both virtual and concrete manipulatives increased the performance of all students' math fact fluency (the number of one-digit by one-digit multiplication problems correctly solved per minute) and accuracy (the percentage of two-digit by one-digit multiplication problems correctly solved), students demonstrated a greater rate of increase (i.e., trend) and long-lasting effect when using virtual manipulatives than they did when using concrete manipulatives. The research questions were addressed as follows.

\section{Research Question 1. Math Fact Fluency in One-Digit by One-Digit Multiplication Immediate Effect}

Intervention effects of using both types of manipulatives were examined using three aspects of visual analysis (level, trend, and stability) and calculation of PND (see Table 3 and Figure 2). First, mean and median levels increased from baseline to intervention for both intervention conditions (mean level change: +6.20 for virtual and +4.19 for concrete; median level change: +17 for virtual and +15 for concrete), with greater increases in the virtual manipulative intervention than in the concrete manipulative intervention. Second, the trend between baseline and intervention phases was greater in the virtual manipulative intervention condition $(M=8 ; S D=3.14)$ than in the concrete manipulative intervention $(M=1.25 ; S D=5.41)$, indicating that the rate of improvement was greater when using virtual manipulatives than when using concrete manipulatives. While all eight students demonstrated positive trends (ranging from +1.5 to +11.5 , but mostly between +8 and +11.5 ) in that their performance on one-digit by one-digit multiplication facts when using virtual manipulatives changed in a therapeutic direction, only three students demonstrated positive trends (ranging from +1.5 to +11.5 ) with the use of concrete manipulatives. 
Table 3: Visual Analysis and Effect Size Calculation

\begin{tabular}{|c|c|c|c|c|c|c|c|c|c|}
\hline \multirow[b]{2}{*}{ Descriptive } & \multicolumn{8}{|c|}{ Student } & \multirow[b]{2}{*}{ Total } \\
\hline & A & B & C & D & $E$ & $\mathrm{~F}$ & G & $\mathrm{H}$ & \\
\hline \multicolumn{10}{|l|}{ Level } \\
\hline$M_{B L}$ & 15.33 & 13.67 & 13 & 7.33 & 9.67 & 11.67 & 9.33 & 3.33 & $\begin{array}{l}10.42 \\
(3.86)\end{array}$ \\
\hline$M_{I N T-V}$ & 17.6 & 18.75 & 18.2 & 14.2 & 13.4 & 14 & 17.4 & 19.4 & $\begin{array}{l}16.62 \\
(2.37)\end{array}$ \\
\hline$M_{I N T-C}$ & 17.5 & 17.25 & 13 & 11.75 & 12.5 & 15.5 & 16 & 13.33 & $\begin{array}{l}14.60 \\
(2.23)\end{array}$ \\
\hline \multicolumn{10}{|l|}{ Level Change } \\
\hline$M_{I N T-V}-M_{B L}$ & 2.27 & 5.08 & 5.2 & 6.87 & 3.73 & 2.33 & 8.07 & 16.07 & 6.20 \\
\hline$M_{I N T-C}-M_{B L}$ & 2.17 & 3.58 & 0 & 4.42 & 2.83 & 3.83 & 6.67 & 10 & 4.19 \\
\hline$M e_{I N T-V}-M e_{B L}$ & 3 & 4.5 & 2 & 6 & 1 & 1 & 8 & 20 & 17 \\
\hline$M e_{I N T-C}-M e_{B L}$ & 3 & 4 & -2 & 4 & 3.5 & 4 & 6 & 10 & 15 \\
\hline \multicolumn{10}{|l|}{ Trend } \\
\hline$T_{B L}$ & 1 & -2 & 0 & -1 & 7 & 0 & 4 & 4 & $\begin{array}{c}1.62 \\
(3.07)\end{array}$ \\
\hline$T_{I N T-V}$ & 8 & 1.5 & 10 & 9.5 & 9 & 5.5 & 9 & 11.5 & $\begin{array}{c}8 \\
(3.14)\end{array}$ \\
\hline$T_{\text {INT }-C}$ & -1 & 6.5 & 1.5 & -1.5 & -6 & -1 & 0 & 11.5 & $\begin{array}{c}1.25 \\
(5.41) \\
\end{array}$ \\
\hline \multicolumn{10}{|l|}{ Stability } \\
\hline$S_{I N T-V}$ & 0.6 & 1 & 0.2 & 0.6 & 0.4 & 0.4 & 0.6 & 0.2 & 0.5 \\
\hline$S_{\text {INT-C }}$ & 1 & 0.5 & 1 & 0.5 & 0.5 & 1 & 1 & 0.5 & 0.75 \\
\hline \multicolumn{10}{|l|}{ PND } \\
\hline$P N D_{I N T-V}$ & 0.6 & 1 & 0.6 & 0.8 & 0.2 & 1 & 0.8 & 0.8 & 0.73 \\
\hline$P N D_{I N T-C}$ & 0.75 & 0.5 & 0.33 & 0.5 & 0.25 & 1 & 1 & 0.67 & 0.63 \\
\hline
\end{tabular}

Note. $M_{B L}=$ Mean for baseline; $M_{I N T-V}=$ Mean for Intervention with Virtual Manipulative; $M_{I N T-C}=$ Mean for Intervention with Concrete Manipulative; $M e_{B L}=$ Median for baseline; $M e_{I N T-V}=$ Median for Intervention with Virtual Manipulative; $M e_{I N T-C}=$ Median for Intervention with Concrete Manipulative; $T_{B L}=$ Trend for baseline; $T_{I N T-V}=$ Trend for Intervention with Virtual Manipulative; $T_{I N T-C}=$ Trend for Intervention with Concrete Manipulative; $S_{\text {INT-V }}=$ Stability for Intervention with Virtual Manipulative; $S_{\text {INT-C }}=$ Stability for Intervention with Concrete Manipulative; PND=Percentage of nonoverlapping data.

Third, intervention data were more variable in the virtual manipulative condition than in the concrete manipulative condition, with stability indexes of 0.5 and 0.75 , respectively. This indicates that $50 \%$ and $75 \%$ of students' scores fell within $20 \%$ of the overall mean for the virtual and concrete manipulative intervention phase, respectively, which shows that the intervention for virtual manipulatives was less stable that of concrete manipulatives (Gast \& Spriggs, 2010). Last, effect size (the quantified value of performance difference between baseline and intervention, measured using PND) was greater in the intervention of virtual manipulatives (PND $=73 \%$, fairly effective) than that of concrete manipulatives (PND $=63 \%$, mildly effective), which demonstrated the stronger immediate effect of the intervention using virtual manipulatives on one-digit by one-digit multiplication fact fluency. 
Figure 2: Average Math Fact Fluency in One-Digit by One-Digit Multiplication

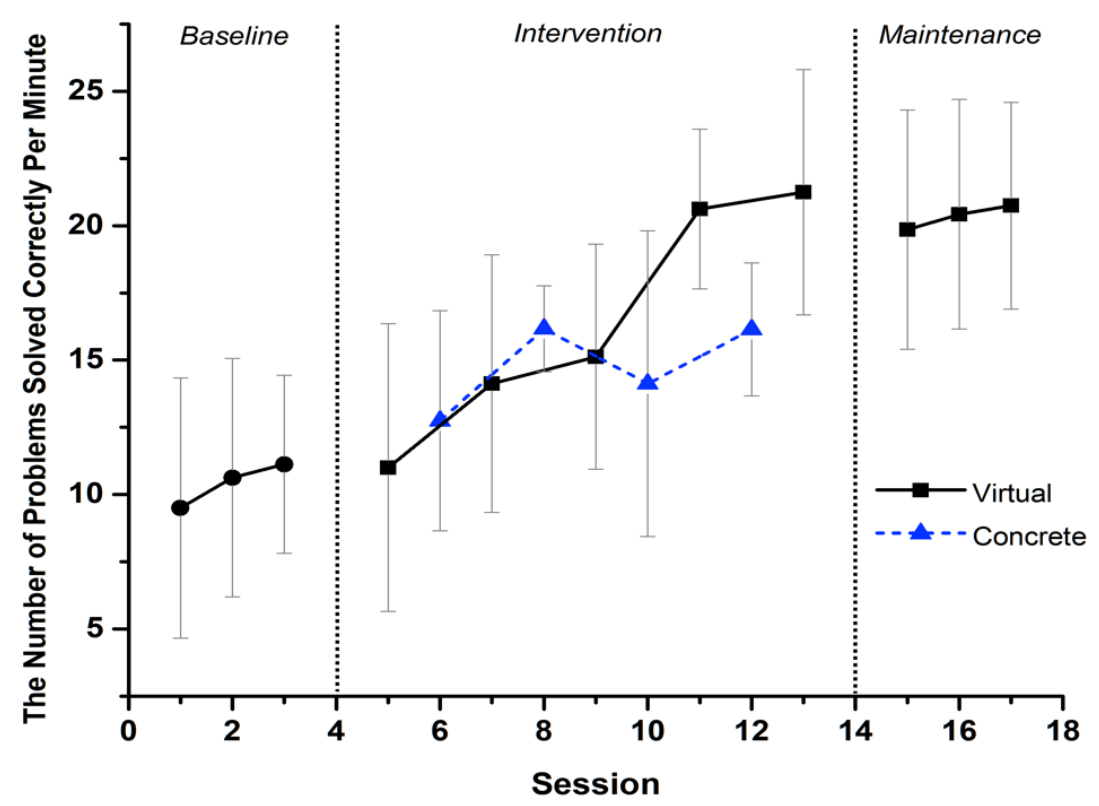

\section{Maintenance Effect}

Two weeks after the end of the period of intervention using virtual manipulatives, fact fluency was measured over three consecutive sessions to examine the maintenance effect of virtual manipulatives (see Figure 2). The overall mean level increased by 9.5 from baseline and by 3.3 from the intervention, ranging from -3.53 to 6.6. The intervention effects were either maintained or improved for all eight students except for one. This student achieved mean score of 14.67 across the three maintenance sessions, which was a little less than the mean score of the virtual manipulative intervention condition (18.2) and somewhat less than the last score of the intervention (22).

\section{Math Fact Accuracy in Two-Digit by One-Digit Multiplication}

In addition to the effect comparison between virtual and concrete manipulatives, we examined effects of virtual manipulatives on math fact accuracy in two-digit ( $>20$ ) by one-digit multiplication. Accuracy was measured by calculating percentage of correct items at four different time points: before, during, immediately after, and two weeks after the intervention. The overall mean accuracy for the eight students increased from $40.65 \%$ to $65 \%$ (baseline: 40.65\%; during intervention: 55\%; immediately after intervention: 65\%; and two weeks after intervention: $87.50 \%$ ), demonstrating the effects of virtual manipulatives in reducing errors when solving multiplication problems.

\section{Research Question 2: Social Validity from Perceptions of Students and Teacher Toward Using Technology in Learning and Teaching Math}

All eight students responded that they had no prior experience using virtual manipulatives in either home or school learning environments, which corresponded with the student 
information reported by the teacher. Perception and confidence levels toward using technology were rather mixed: six students responded that virtual manipulatives were preferred, one student responded that there were not sure or did not know, and one student responded in favor of concrete manipulatives.

The teacher was asked two questions. The first question was, "From the perspective of a teacher who has actually used and implemented virtual manipulatives (i.e., from a practical standpoint), how would you evaluate the potential for using virtual manipulatives in teaching math to students with LD?" The teacher agreed manipulatives were effective regardless of their types. The teacher had an optimistic view of the potential for virtual manipulatives in particular based on several benefits observed from his students. The teacher stated that virtual manipulatives allowed students to see and experience the connection of representations to mathematical problems on the screen in more flexible ways. Also, he stated that one of the benefits includes built-in assessments that immediately test the comprehension of various problems until students master each concept.

The second question was, "What were the challenges or limitations in using virtual manipulatives in teaching students with LD, and what do you think needs to be improved or changed given the fact that using technology in education is unavoidable?" The teacher stated that several of the students experienced difficulty in working on math problems using the virtual manipulatives at the beginning of the intervention, which may have been due to the learning curve that came with learning a new online program. The teacher then stated that the students gradually adjusted to the new platform of learning and presented a sharp improvement in math fact fluency. Additionally, the teacher pointed out that lack of resources and accessibility to educational technology in rural schools are limitations that may hinder equal access to education opportunity. He stated that the ambiguity of virtual manipulatives leaves an additional element that needs to be learned by students as part of the technology experience and also noted the need for special education teachers to have expertise in the use of those technology tools. Given that students with LD need more direct and explicit support than general education peers, the teacher stated that a tactile element needs to be incorporated to maximize the effects of virtual manipulatives. The teacher concluded that the effectiveness of these technologies still needs to be assessed, particularly in rural areas.

\section{DISCUSSION}

As the use of technology has become more prevalent within the educational environment over the past decade, increased attention has been paid to integration of technology into mathematics practices in K-12 education. A survey conducted by the National Center for Education Statistics (NCES, 2018b) concluded that in 2015, 94\% of children ages 3 to 18 had a computer at home and $61 \%$ had internet access. Additionally, in 2009 the NCES found that $97 \%$ of teachers had computers in the classroom. With such changes to K-12 educational settings, additional technology-based practices such as virtual manipulatives are emerging to support 
student engagement and instruction (Musti-Rao et al., 2015). Recent studies have found that since using virtual manipulatives can produce consistent or even better student outcomes than using concrete manipulatives, they are a promising approach to transitioning to technologyinfused math instruction (Bouck \& Flanagan, 2010). The use of virtual manipulatives also offers students, especially secondary age students, an age-appropriate alternative to concrete manipulatives, which are more commonly used with younger children (Witzel, Mercer, \& Miller, 2003). The use of virtual manipulatives in classrooms is becoming more common practice due to new types of technologies for students (Bouck et al., 2018; Satsangi \& Bouck, 2014; Satsangi et al., 2018).

Unfortunately, too little research has been done with students with disabilities, particularly those in rural areas, which may widen the achievement gap between them and students without disabilities in the era of digital and virtual learning. In particular, students living in rural areas generally have limited access to technology and internet access at home (NCES, 2018b) and rarely receive technology-infused instruction at school due to the many challenges faced by rural schools in terms of technology accessibility, implementation, and resources. These challenges adversely affect academic opportunities for students, which may also disrupt equity in learning and teaching.

Legislation such as the Individuals with Disability Act (IDEA, 2004) has mandated that students with disabilities should have access to an adequate general education curriculum. National organizations such as NCTM (2019) have advocated for high-quality teaching and learning mathematics for each and every student regardless of disability, level of achievement, socioeconomic status, or geographical location. Still, approximately 6.7 million students that have been identified under the IDEA as having a disability, and particularly the $34 \%$ of those students who have LD (National Center of Education Statistics, 2018), have been shown to have a significant achievement gap between them and students without disabilities where more than half of students with LD scored at the basic level for mathematics and this gap increased to almost 80\% when they entered high school (National Assessment for Education Progress, 2019).

With this new era of education where technology-infused instruction, a new platform of instruction, is highly desired, it has been increasingly important to address this achievement gap between students with and without disabilities. Therefore, the current study explored the potential for using virtual manipulatives to build math fact fluency for single-digit by single-digit multiplication. We examined whether the previously proven effects of concrete manipulatives on students' math fact fluency can carry over into those of virtual manipulatives and therefore be an effective alternative tool to concrete manipulatives. Additionally, we explored future directions for practices for effective use of virtual manipulatives in teaching math for students with LD. In particular, we discussed educational implications for designing and planning effective instruction incorporating virtual manipulatives by examining the technology limitations in rural areas and their derived impact on virtual instruction. Moreover, we discussed the implications of our findings for virtual learning during the COVID-19 pandemic. 
Overall, our findings indicate that the usage of virtual manipulatives is promising, with meaningful implications for practitioners. One aspect that is notable is the significant upward trend when using virtual manipulatives during intervention and the continued growth in accuracy even two weeks after the conclusion of interventions.

\section{Practitioners' Perspectives on Potential for Virtual Manipulatives}

Applications where virtual manipulatives can be used are seen positively from practitioners' perspectives because of their potential to have impact on student learning. For example, educational applications that utilize virtual manipulatives allow them to be manipulated dynamically and flexibly on a computer or tablet PC screen, providing an enriched experience to students. Another positive is that formative assessment can be built in to assess students' comprehension of various problems and correct any errors or misconception immediately. Some newer programs incorporate a tactile element using touchscreens, which will provide more opportunities to approach learning math. While training may be needed for both teachers and students for them to be able to utilize other technology tools, using virtual manipulatives themselves is not very different from using concrete manipulatives, as they work in a similar way in many aspects.

Students with LD require support that is often more explicit, direct, and intensive than what their general education peers need. The ambiguity of virtual manipulatives creates an additional element that needs to be learned by students as part of the technology experience. This is where a special educator's expertise in the use of these educational tools is paramount. Being able to guide students through the use of these instruments concisely and effectively will benefit students' chances of closing achievement gaps. With practice, students can move into a routine where using virtual manipulatives becomes clearer and more concise, allowing students to increase their understanding of the mathematical objectives teachers are striving to achieve. Technologies that can more closely connect the virtual world of mathematical manipulatives with that of the physical can offer better instruments for student achievement in mathematics, but the effectiveness of these technologies needs to be continuously assessed.

\section{Implications to Virtual Learning}

Student development in mathematics has for years benefited from the use of concrete manipulatives. Students have been able to use this evidence-based learning strategy to organize, create, and actually touch these manipulatives with the goal of increased mathematical comprehension, so rather than choosing one over the other, using a combination of concrete and virtual manipulatives may be able to enhance student learning outcomes. However, in the current COVID-19 climate where much instruction has been restricted to online environments with no physical contact, using concrete manipulatives in instruction may not be possible. Although anecdotal reports have shown that some students have seemed to benefit 
from distance learning, many have reported that the majority of students have been falling behind academically.

The implications of the use of visual manipulatives for student achievement are still uncertain due to the current pandemic. However, the modality of distance learning has provided a platform for the extensive use of virtual manipulatives. Current technologies have been adapted to virtual manipulatives with the use of touch screens, making virtual manipulatives more tactile and kinesthetic. With the advent of new technologies such as augmented reality and virtual reality, the possibilities for virtual manipulatives are vast, as shown from our findings. These educational tools could in future be adapted for practitioners and teachers to use in virtual and face-to-face environments.

\section{Implications for Education in Rural Schools}

It is unknown the extent to which virtual manipulatives have been used during the COVID-19 pandemic. However, one area that has seen improvements in technology accessibility has been rural school districts. To allow all students to access instruction and the curriculum, local educational authorities along with public and private agencies have worked to improve the infrastructure of these technologies in these districts. Improvements have not only been seen in large districts but rural districts as well. These improvements will have both positive and negative effects in smaller districts. The new technologies will allow these districts to differentiate instruction that was previously impossible for rural districts. For example, Google Classroom has been widely used for years by large districts. However, these districts were able to provide one-to-one access for their students when utilizing this technology. Rural districts will now have the capability to provide this resource to students. However, many teachers will need to receive professional development and training on these technologies before they can successfully be implemented. Finding time to train teachers and roll out new technologies will be a struggle for districts that adopt any new programs. However, these technologies are now widely available to every student. The implication for teachers is that technology is here to stay and will be interwoven with current and future classroom practices.

\section{Limitations and Future Direction}

Given the nature and purpose of action research, the current study contains the limitations and several factors that are naturally embedded in actual classroom settings. Four main limitations were found that provide guidance for research and practical actions in the future. First, limitations in technology at the rural school have made the use of virtual manipulatives difficult. At the rural school where this study took place, the introduction of technology has been slow, such that the school district technology framework is about 10 years behind most other school districts around the state. The lack of access to technology for these students seems to have played a role in the results of the virtual manipulative interventions, which also signals that more technological resources and support need to be provided to rural schools for equal access and equal education opportunity. 
Second, students' lack of training in the use of virtual manipulatives and online programs made using virtual manipulatives difficult. Considering the lack of resources, it is likely that a school with students that have been more exposed to technology would have transitioned more easily into using virtual manipulatives as an intervention for multiplication problem solving. It would be advantageous for students to be trained in these new technologies before using them as an intervention.

Third, the current study examined the intervention effect only on multiplication math fact fluency that is a small part of mathematical understanding, which limits our findings to be generalized for an overall understanding of mathematics. Future study will address other mathematical areas for a larger grade span. Fourth, social validity was only examined for the implementation of intervention (independent variable) but students' outcome (dependent variable).

Regardless, our findings presented a positive potential for using virtual manipulatives. Future research can address the limitations by providing training sessions for utilization of virtual manipulatives before and during intervention and extending the intervention period for virtual manipulatives. Additionally, future research can look at how virtual manipulatives can be used to increase other mathematics domains and skills such as discourse, creative thinking, and problem-solving abilities in the classroom. Moreover, future study can additionally examine social validity on dependent variables (i.e., behavioral goals and outcomes that are aimed to be achieved) to strengthen the findings.

\section{REFERENCES}

Agrawal, J., \& Morin, L. L. (2016). Evidence-Based Practices: Applications of Concrete Representational Abstract Framework across Math Concepts for Students with Mathematics Disabilities. Learning Disabilities Research \& Practice, 31(1), 34-44.

Barlow, D. H., \& Hayes, S. C. (1979). Alternating treatments design: One strategy for comparing the effects of two treatments in a single subject. Journal of applied behavior analysis, 12(2), 199-210.

Becker, A., McLaughlin, T., Weber, K. P., \& Gower, J. (2009). The effects of copy, cover and compare with and without additional error drill on multiplication fact fluency and accuracy. Electronic Journal of Research in Educational Psychology, 7, 747-760.

Berrett, A. N., \& Carter, N. J. (2018). Imagine math facts improves multiplication fact fluency in third-grade students. Journal of Behavioral Education, 27(2), 223-239.

Billington, E. J., \& Skinner C. H. (2002). Getting students to choose to do more work: Evidence of the interspersal procedure. Journal of Behavioral Education, 11(2), 105- 106.

Bottge, B. A., Ma, X., Gassaway, L., Toland, M. D., Butler, M., \& Cho, S.-J. (2014). Effects of Blended Instructional Models on Math Performance. Exceptional Children, 80(4), 423437. 
Bouck, E. C., \& Flanagan, S. M. (2010). Virtual Manipulatives: What They Are and How Teachers Can Use Them. Intervention in School and Clinic, 45(3), 186-191.

Bouck, E. C., Satsangi, R., \& Park, J. (2018). The concrete-representational-abstract approach for students with learning disabilities: An evidence-based practice synthesis. Remedial and Special Education, 39(4), 211-228.

Bolyard, J., \& Moyer-Packenham, P. (2012). Making Sense of Integer Arithmetic: The Effect of Using Virtual Manipulatives on Students' Representational Fluency. Journal of Computers in Mathematics and Science Teaching, 31(2), 93-113.

Bradbury-Huang, H. (2010). What is good action research? Why the resurgent interest? Action Research, 8(1), 93-109.

Bryant, D. P., Bryant, B. R., \& Hammill, D. D. (2000). Characteristic behaviors of students with LD who have teacher-identified math weaknesses. Journal of learning disabilities, 33(2), 168-177.

Cates, G. L., \& Rhymer, K. N. (2003). Examining the relationship between mathematics anxiety and mathematics performance: An instructional hierarchy perspective. Journal of Behavioral Education, 12(1), 23-34.

Center for Data-Driven Reform in Education (CDDRE). (2009). Effective Programs in Elementary Mathematics: A Best-Evidence Synthesis. Educator's Summary. Center for Data-Driven Reform in Education. Center for Data-Driven Reform in Education. Retrieved from https://files.eric.ed.gov/fulltext/ED527642.pdf

Clements, D. H. (1999). Concrete' manipulatives, concrete ideas. Contemporary Issues in Early Childhood, 1(1), 45-60.

Codding, R. S., Burns, M. K., \& Lukito, G. (2011). Meta-analysis of Mathematic Basic Fact Fluency Interventions: A Component Analysis. Learning Disabilities Research \& Practice, 26(1), 36-47.

Coffee, G., \& Kratochwill, T. R. (2014). Alternating Treatments Designs. Wiley StatsRef:

Statistics Reference Online, 1-4.

https://doi.org/10.1002/9781118445112.stat06200.pub2

Common Core State Standards Initiative. (2010). Common Core State Standards for mathematics. Retrieved from http://www.corestandards.org/assets/CCSSI_Math\%20Standards.pdf

Deubel, P. (2010). CT4ME.NET: Computing Technology for Math Excellence: Math manipulatives. Retreived from: https://www.ct4me.net/about this site.htm

Fleischner, J. E., \& Manheimer, M. A. (1997). Math interventions for students with learning disabilities: Myths and realities. School Psychology Review, 26(3), 397-413.

Fletcher, J. M., \& Grigorenko, E. L. (2017). Neuropsychology of learning disabilities: The past and the future. Journal of the International Neuropsychological Society, 23(9-10), 930. 
Flores, M. M. (2010). Using the concrete-representational-abstract framework to teach subtraction with regrouping to students at risk for failure. Remedial and Special Education, 31, 195-207. doi:10.1177/0741932508327467

Flores, M. M., \& Kaylor, M. (2007). The effects of a direct instruction program on the fraction performance of middle school students at-risk for failure in mathematics. Journal of Instructional Psychology, 34(2), 84.

Fuchs, L. S. et al. (2011). The development of arithmetic and word problem skill among students with mathematics disability. 434-444. In J. M. Kauffman, D. P. Hallahan (Ed.). Handbook of special education (pp. 434-444). Routledge.

Geary, D. C., Hoard, M. K., Nugent, L., \& Bailey, D. H. (2012). Mathematical cognition deficits in children with learning disabilities and persistent low achievement: A five-year prospective study. Journal of Educational Psychology, 104, 206-223. doi:10.1037/a0025398

Hine, G. S. C. (2013). The Importance of Action Research in Teacher Education Programs. Issues in Educational Research, 23(2), 151-163.

Hudson, P., \& Miller, S. P. (2006). Designing and implementing mathematics instruction for students with diverse needs. Pearson Education.

Hirvonen, R., Tolvanen, A., Aunola, K., \& Nurmi, J. E. (2012). The developmental dynamics of task-avoidant behavior and math performance in kindergarten and elementary school. Learning and Individual Differences, 22(6), 715-723.

Hwang, J., \& Riccomini, P. J. (2016). Enhancing mathematical problem solving for secondary students with or at risk of learning disabilities: A literature review. Learning Disabilities Research \& Practice, 31(3), 169-181.

Hwang, J., Riccomini, P. J., Hwang, S. Y., \& Morano, S. (2019). A systematic analysis of experimental studies targeting fractions for students with mathematics difficulties. Learning Disabilities Research \& Practice, 34(1), 47-61.

Hwang, J., Riccomini, P. J., \& Morano, S. (2019). Examination of Cognitive Processes in Effective Algebra Problem-Solving Interventions for Secondary Students with Learning Disabilities. Learning Disabilities: A Contemporary Journal, 17(2), 205-220.

Individuals with Disabilities Education Act, 20 U.S.C. § 1400 (2004)

Jayanthi, M., Gersten, R., \& Baker, S. (2008). Mathematics Instruction for Students with Learning Disabilities or Difficulty Learning Mathematics: A Guide for Teachers. Center on Instruction.

Jones, J. P., \& Tiller, M. (2017). Using Concrete Manipulatives in Mathematical Instruction. Dimensions of Early Childhood, 45(1), 18-23.

Kelley, B. (2008). Best practices in curriculum-based evaluation and math. In A. Thomas \& J. Grimes (Eds.), Best practices in school psychology, (5th ed.) (pp. 419-438). Bethesda, MD: National Association of School Psychologists.

Lewin, K. (1946). Action research and minority problems. Journal of social issues, 2(4), 34-46. 
Maccini, P., Mulcahy, C. A., \& Wilson, M. G. (2007). A follow-up of mathematics interventions for secondary students with learning disabilities. Learning Disabilities Research \& Practice, 22, 58-74.

Miller, S. P., \& Mercer, C. D. (1997). Educational aspects of mathematics disabilities. Journal of Learning Disabilities, 30(1), 47-56.

Miller, S. P., \& Kaffar, B. J. (2011). Developing addition and regrouping competence among second grade students with mathematics difficulties. Investigations in Mathematics Learning, 4(1), 25-51.

Milton, J. H., Flores, M. M., Moore, A. J., Taylor, J. J., \& Burton, M. E. (2019). Using the Concrete-Representational-Abstract Sequence to Teach Conceptual Understanding of Basic Multiplication and Division. Learning Disability Quarterly, 42(1), 32-45.

Morgan, P. L., Farkas, G., Hillemeier, M. M., \& Maczuga, S. (2016). Who Is at Risk for Persistent Mathematics Difficulties in the United States? Journal of Learning Disabilities, 49(3), 305-319.

Moyer, P. S., Bolyard, J. J., \& Spikell, M. A. (2002). What Are Virtual Manipulatives? Teaching Children Mathematics, 8(6), 372-77.

Nelson, N. J., Fien, H., Doabler, C. T., \& Clarke, B. (2016). Considerations for Realizing the Promise of Educational Gaming Technology. TEACHING Exceptional Children, 48(6), 293-300.

National Center for Education Statistics (2018a). Children and Youth with Disabilities. Retrieved from https://nces.ed.gov/programs/coe/indicator cgg.asp

National Center for Education Statistics (2018b). Computer and internet use. Retrieved from: https://nces.ed.gov/fastfacts/display.asp?id=46

National Council of Teachers of Mathematics. (2019). Mission Statement. Reston, VA: NCTM.

Poncy, B. C., \& Skinner, C. H. (2006). Implementation Guidelines: Detect, Practice, and Repair: The Effects of a Classwide Intervention on Elementary Students' Math-Fact Fluency. Journal of Evidence-Based Practices for Schools, 7(1), 69-72.

National Mathematics Advisory Panel (NMAP). (2008). Foundations for success: The final report of the National Mathematics Advisory Panel. Washington, D.C.: U.S. Department of Education.

Pratt, S. S., \& Eddy, C. M. (2017). Selecting Tools to Model Integer and Binomial Multiplication. Journal of Mathematics Education at Teachers College, 8(2), 31-40.

Ortiz, E. (2017). Pre-Service Teachers' Ability to Identify and Implement Cognitive Levels in Mathematics Learning. Issues in the Undergraduate Mathematics Preparation of School Teachers, 3.

Raghubar, K., Cirino, P., Barnes, M., Ewing-Cobbs, L., Fletcher, J., \& Fuchs, L. (2009). Errors in multi-digit arithmetic and behavioral inattention in children with math difficulties. Journal of learning disabilities, 42(4), 356-371. 
Ramos-Christian, V., Schleser, R., \& Varn, M. E. (2008). Math fluency: Accuracy versus speed in preoperational and concrete operational first and second grade children. Early Childhood Education Journal, 35(6), 543-549. doi: 10.1007/s10643-008-0234-7

Rave, K., \& Golightly, A. F. (2014). The Effectiveness of the Rocket Math Program for Improving Basic Multiplication Fact Fluency in Fifth Grade Students: A Case Study. Education, 134(4), 537-547.

Reimer, K., \& Moyer, P. S. (2005). Third-graders learn about fractions using virtual manipulatives: A classroom study. Journal of Computers in Mathematics and Science Teaching, 24, 5-25.

Richland, L. E., Stigler, J. W., \& Holyoak, K. J. (2012). Teaching the conceptual structure of mathematics. Educational Psychologist, 47(3), 189-203.

Rushton, S. J., Hadley, K. M., \& Stewart, P. W. (2016). Mathematics Fluency and Teaching SelfEfficacy of Teacher Candidates. Journal of the International Society for Teacher Education, 20(2), 48-56.

Sagor, R. (2000). Guiding School Improvement with Action Research: ASCD. Ascd.

Satsangi, R., \& Bouck, E. C. (2014). Using virtual manipulative instruction to teach the concepts of area and perimeter to secondary students with learning disabilities. Learning Disability Quarterly, 38, 174-186. doi:10.1177/0731948714550101

Satsangi, R., Hammer, R., \& Hogan, C. D. (2018). Studying Virtual Manipulatives Paired with Explicit Instruction to Teach Algebraic Equations to Students with Learning Disabilities. Learning Disability Quarterly, 41(4), 227-242.

Saylan, A., Onal, N. T., \& Onal, N. (2018). Using Technology in Education from the Pre-Service Science and Mathematics Teachers' Perspectives. International Education Studies, 11(10), 28-41.

Schmitz, E. A., Jansen, B. R., Wiers, R. W., \& Salemink, E. (2019). Do implicitly measured mathanxiety associations play a role in math behavior? Journal of experimental child psychology, 186, 171-188.

Scruggs, T. E., \& Mastropieri, M. A. (1998). Summarizing Single-Subject Research. Behavior Modification, 22(3), 221-242. doi:10.1177/01454455980223001

Scruggs, T. E., Mastropieri, M. A., \& Casto, G. (1987). The quantitative synthesis of singlesubject research: Methodology and validation. Remedial and Special education, 8(2), 24-33.

Scruggs, T. E., Mastropieri, M. A., Cook, S. B., \& Escobar, C. (1986). Early intervention for children with conduct disorders: A quantitative synthesis of single-subject research. Behavioral Disorders, 11(4), 260-271.

Shaywitz, S. E., Fletcher, J. M., \& Shaywitz, B. A. (1994). Issues in the definition and classification of attention deficit disorder. Topics in Language Disorders, 14, 1-25. 
Shin, M., Bryant, D. P., Bryant, B. R., McKenna, J. W., Hou, F., \& Ok, M. W. (2017). Virtual Manipulatives: Tools for Teaching Mathematics to Students with Learning Disabilities. Intervention in School and Clinic, 52(3), 148-153.

Sideridis, G. D. (2005). Performance approach-avoidance motivation and planned behavior theory: Model stability with Greek students with and without learning disabilities. Reading \& Writing Quarterly, 21(4), 331-359.

Spicer, J. (2000). Virtual Manipulatives: A New Tool for Hands-On Math. ENC Focus 7(4)

Strickland, T. K. \& Maccini, P. (2012). The effects of the concrete-representational abstract integration strategy on the ability of students with learning disabilities to multiply linear expressions within area problems. Remedial and Special Education, 34, 142-153. http://dx.doi.org/10.1177/0741932512441712

Strickland, T. K. \& Maccini, P. (2013). The Effects of the Concrete-Representational-Abstract Integration Strategy on the Ability of Students with Learning Disabilities to Multiply Linear Expressions within Area Problems. Remedial and Special Education, 34(3), 142153.

Strickland, T. K. (2016). Using the CRA-I Strategy to Develop Conceptual and Procedural Knowledge of Quadratic Expressions. TEACHING Exceptional Children, 49(2), 115-125.

Suh, J., \& Moyer, P. S. (2007). Developing students' representational fluency using virtual and physical algebra balances. Journal of Computers in Mathematics and Science Teaching, 26, 155-173.

Suh, J., Moyer, P. S., \& Heo, H.-J. (2005). Examining technologyuses in the classroom: Developing fraction sense using virtual manipulatives concept tutorials. Journal of Interactive Online Learning, 3(4), 1-21.

Taylor, J. (2019). Mission Possible: Getting Teachers into Action Research. ASCD Express, 14(34). Retrieved from:

http://www.ascd.org/ascd-express/vol14/num34/mission-possible-getting-teachers-intoaction-research.aspx

Taylor, J. C. \& Moohr, M. (2018) Four levers for improving teacher prep. ASCD Express, 13(18). Retrieved from http://www.ascd.org/ascd-express/vol13/1318-taylor.aspx

The National Assessment of Educational Progress (2019). Mathematical Assessment Retrieved from https://www.nationsreportcard.gov/math 2017/nation/gaps/?grade=8

Witzel, B. S., Riccomini, P. J., \& Schneider, E. (2008). Implementing CRA with secondary students with learning disabilities in mathematics. Intervention in School and Clinic, 43(5), 270-276

Witzel, B. S., Mercer, C. D., \& Miller, M. D. (2003). Teaching algebra to students with learning difficulties: An investigation of an explicit instruction model. Learning Disabilities Research \& Practice, 18, 121-131. doi:10.1111/1540-5826.00068 
Wu, Q., Lei, P., DiPerna, J. C., Morgan, P. L., \& Reid, E. E. (2015). Identifying Differences in Early Mathematical Skills among Children in Head Start. International Journal of Science and Mathematics Education, 13(6), 1403-1423.

Yakubova, G., Hughes, E. M., \& Shinaberry, M. (2016). Learning with Technology: Video Modeling with Concrete-Representational-Abstract Sequencing for Students with Autism Spectrum Disorder. Journal of Autism and Developmental Disorders, 46(7), 2349-2362.

Ysseldyke, J., Thill, T., Pohl, J., \& Bolt, D. (2005). Using Math Facts in a Flash to enhance computational fluency. Journal of Evidence-Based Practices for Schools, 6(1), 59-89. 